Working

Paper

Department

of Economics

$\mathrm{Ca}^{\prime}$ Foscari University of Venice

Guido Cazzavillan Krzysztof Olszewski

Skill-biased technological change and endogenous labor supply in EU Transition Economies and the US 


\title{
Skill-biased technological change and endogenous labor supply in EU Transition Economies and the US
}

\author{
Guido Cazzavillan and Krzysztof Olszewski \\ Università Ca’ Foscari Venezia \\ Department of Economics
}

First Draft: June 2009

\begin{abstract}
In this paper skill-biased technological change is linked with endogenous labor supply which allows for unemployment. This is a novel approach, as the literature on skill-biased technological change considers inelastic labor supply. Elastic labor supply allows us to explain how the observed increasing unemployment of unskilled workers is caused by skill-biased technological change. Our numerical analysis shows that if the skill-biased technological change is not followed by the growth of total factor productivity, then output, physical capital stock and consumption decline. Using empirical data on wages and education, we construct a time series for skill-biased technological change for Poland and the US. The empirical relevance of the model is tested by calibrating it to empirical data for Poland over the period 1996-2006 and US over the period 1992-2008. With only two necessary inputs, share of skilled workers in total population and the technology adopted by firms, this model allows to simulate the future behaviour of the labor market.
\end{abstract}

\section{Keywords}

Skill-biased technological change, Endogenous labor supply, Transition Economies

JEL Codes

O11, O3, O41

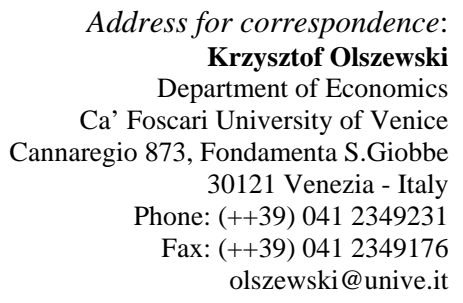

This Working Paper is published under the auspices of the Department of Economics of the Ca' Foscari University of Venice. Opinions expressed herein are those of the authors and not those of the Department. The Working Paper series is designed to divulge preliminary or incomplete work, circulated to favour discussion and comments. Citation of this paper should consider its provisional character. 


\section{Introduction}

Since Transition Economies allow for the inflow of foreign direct investment, there can be observed a significant increase of the skill premium, increase of unemployment of unskilled workers and economic growth. The literature considers two ways through which foreign direct investment (FDI) affects the growth of Transition Economies. First, FDI directly increases the physical capital stock. Secondly, there might exist knowledge and technology spillovers. Smarzynska Javorcik (2004) performed an empirical study using firm level data on multinational enterprises in Lithuania. She found significant positive productivity spillovers through backward linkages. No intra-sectoral spillovers were found. Smarzynska Javorcik (2004) names three ways through which spillovers might go to domestic intermediate goods suppliers: (i) direct knowledge transfers from foreign customers to local suppliers; (ii) higher requirements for product quality and on-time delivery introduced by multinationals, which provide incentives to domestic suppliers to upgrade their production management or technology; and (iii) multinational entry increasing demand for intermediate products, which allows local suppliers to reap the benefits of scale economies.

The lack of motivation and quality control had a negative effect on productivity in EU Transition Economies ${ }^{1}$. The presence of multinationals leads to skill-biased technological change (SBTC) and total factor productivity (TFP) growth. Both processes are considered as strictly exogenous. Using elastic labor supply the model explains the observed increasing unemployment of unskilled workers and links it to skill-biased technological change. The SBTC literature ${ }^{2}$ assumes that labor supply is inelastic. While this assumption seems to match the labor market in rich OECD countries, it is clearly at odds with the high unemployment in Transition Economies. Machin and Van Reenen (1998, p. 1217) state: "We cannot deduce the full effect of technology on labor market structure without also closing the model by looking at the supply side effects and the nonmanufacturing sector, which is beyond the scope of this paper". Our model deals exactly with this problem. It can be applied to any Transition Economy and to any developed country if SBTC is considered as an exogenous process. We calibrate the model and test its empirical relevance using data for Poland, which is the largest Transition Economy. Moreover, we test it for the US.

The paper is organized as follows. The model is presented in section 2. First, we model the production function with skilled and unskilled labor (section 2.1). Sec-

\footnotetext{
*Participants of the Warsaw International Economic Meeting 2008, Milan DEAS Workshop on Growth 2008, Bielefeld EBIM workshop 2008, the WISE seminar at University of Venice and the research seminar at Warsaw School of Economics made useful comments.

${ }^{1}$ The countries of interest are: the Czech Republic, Hungary, Poland, the Slovak Republic and Slovenia.

${ }^{2}$ A review of the literature can be found in Acemoglu (2002) and Machin (2008).
} 
ondly, we provide empirical evidence for skill-biased technological change and calculate its time-series (section 2.2). In the next step, the household problem is solved (section 2.3). Workers supply labor depending on wages. In section 3 the parameters are calibrated and a numerical analysis is performed. This allows to test the model's empirical relevance. Section 4 concludes the paper.

\section{The model}

We consider an economy populated by an infinite number of households and firms. The economy is perfectly competitive and everybody is a price taker. Households consist of skilled and unskilled workers who provide a fraction of their time to the production of a representative good.

The lack of data leads us to study the effect of SBTC by focusing on total output. It would be more appropriate to focus purely on firms in the manufacturing sector. To our best knowledge it is impossible to collect the necessary data on education of workers in given sectors of the economy. Smarzynska Javorcik (2004) states that in the dataset she uses one cannot distinguish between skilled and unskilled workers. The approach to look at the whole economy can be motivated by the following fact: Firms which are affected by the spillovers use the acquired knowledge in different production processes and supply many firms. Smarzynska Javorcik (2004) presents anecdotal evidence for this with a Czech firm. Diverse studies show that there is always SBTC, and we look at its average. SBTC appears in a similar manner in different sectors in advanced countries (Berman, Bound and Machin 1998) while it is sector biased in Transition Economies (Esposito and Steher 2007). Moreover, there is empirical evidence that MNCs invest in the more productive firms, thus mainly those are affected by SBTC. Bearing this in mind, we study the effect of SBTC at the GDP level.

\subsection{The productive sector}

In setting up the productive sector we base on the specification of Caselli and Coleman (2006):

$$
y=k^{\alpha}\left[\left(A_{u} L_{u}\right)^{\sigma}+\left(A_{s} L_{s}\right)^{\sigma}\right]^{(1-\alpha) / \sigma}
$$

Here $L_{u}$ is unskilled labor and $L_{s}$ is skilled labor. The elasticity of substitution between skilled and unskilled workers is $\varepsilon=1 /(1-\sigma)$ and lies in the range $(1,2)$ (see Autor, Katz and Krueger (1998)).

We modify the model and allow the workers to decide how much labor they supply. The households live infinitely. Each household consists of an exogenously given fraction 
$u$ of unskilled and a fraction $1-u$ of skilled workers. Each type of worker is endowed with one unit of time. The unskilled (skilled) worker devotes a fraction of time $l(h)$ to work and the residual $1-l(1-h)$ to leisure. In aggregate terms, when $N$ denotes the total available labor force, the labor input of unskilled is $u N l$ and of skilled $(1-u) N h$. I divide the production function by $N$ and get per capita terms:

$$
y=k^{\alpha}\left[\left(A_{u} u l\right)^{\sigma}+\left(A_{s}(1-u) h\right)^{\sigma}\right]^{(1-\alpha) / \sigma}
$$

First, we present the modified Caselli and Coleman (2006) model in a form which is convenient for the further analysis:

$$
y=A^{1-\alpha} k^{\alpha}\left[(\phi u l)^{\sigma}+((1-\phi)(1-u) h)^{\sigma}\right]^{(1-\alpha) / \sigma}
$$

$A$ denotes total factor productivity and $\phi$ and $1-\phi$ denotes the productivity of each kind of labor. After profit maximization, thus differentiation of equation (2.3) with respect to the inputs $u l,(1-u) h$ and $k$, we obtain:

$$
\begin{gathered}
w_{l}=(1-\alpha) A^{1-\alpha} k^{\alpha}\left[(\phi u l)^{\sigma}+((1-\phi)(1-u) h)^{\sigma}\right]^{(1-\alpha) / \sigma-1} \phi^{\sigma}(u l)^{\sigma-1} \\
w_{h}=(1-\alpha) A^{1-\alpha} k^{\alpha}\left[(\phi u l)^{\sigma}+((1-\phi)(1-u) h)^{\sigma}\right]^{(1-\alpha) / \sigma-1}(1-\phi)^{\sigma}((1-u) h)^{\sigma-1} \\
r=\alpha A^{1-\alpha} k^{\alpha-1}\left[(\phi u l)^{\sigma}+((1-\phi)(1-u) h)^{\sigma}\right]^{(1-\alpha) / \sigma}
\end{gathered}
$$

Dividing $w_{h}$ by $w_{l}$ we get the skill premium:

$$
\frac{w_{h}}{w_{l}}=\left(\frac{1-\phi}{\phi}\right)^{\sigma}\left(\frac{1-u}{u} \frac{h}{l}\right)^{\sigma-1}
$$

The skill premium is increasing in $1-\phi$ and decreasing in $(1-u) h$.

\subsection{Facts on TFP and SBTC}

The phenomenon of increased non-production worker share in the wage bill in OECD countries is studied by Machin and Van Reenen (1998) and Berman, Bound and Machin (1998). Moreover, the latter state that less skilled workers sometimes also face increased unemployment. They claim that "SBTC was pervasive over the past two decades, occurring simultanously in most, if not in all, developed countries" (Berman, Bound and Machin 1998, p. 1246). This change occurred in the US as well as in other developed countries and the most affected industries were the skill-intensive ones, namely machinery, electrical machinery and printing and publishing (Berman, Bound and Machin 1998). A very similar pattern can be observed in Transition Economies. Esposito and Steher 
(2007) provide a literature overview. Focusing on the period 1995-2003 and using data at the 14 industries level (DA-DN code) Esposito and Steher (2007) find evidence of SBTC. However, there is a sector bias as SBTC was concentrated in the skill-intensive and medium skill industries in Hungary and Poland. Another study, performed by Lorentowicz, Marin and Raubold (2005) at a higher disaggregation level (23 ISIC industries) in the period 1994-2002 links FDI with an increase of skilled labor share and wage inequality in Poland.

In order to understand the continuous and fast economic growth of EU Transition Economies it is important to study the development of total factor productivity (TFP) and the productivity of skilled workers. This approach can be motivated by the results of Hall and Jones (1999), who perform a cross-country study on output differences. They conclude that physical capital and human capital differences explain only a small fraction of differences in output per worker. A large part can be attributed to TFP. The differences in productivity and capital accumulation are driven by the differences in the social infrastructure.

TFP consists of two very important things: technological knowledge and social infrastructure. Technological knowledge allows to produce advanced goods. Social infrastructure determines how efficiently workers work and how much they care about quality. We assume that multinational corporations (MNCs) are able to improve the social infrastructure through backward linkages. MNCs demand skilled workers and create incentives for them to work efficiently and improve the quality of their work. They choose a skillbiased technology and pay the skilled worker a higher wage. Cieślik (2008) presents a model for Developing Economies in which foreign firms pay efficiency wages in order to motivate the workers, and studies conditions under which foreign knowledge, technological change and diffusion of this knowledge to domestic firms appears. The following study motivates that the economic environment has an important effect on the productivity. Hendricks (2002) analyzes the output differences among countries by looking at wages of immigrants in the US. He strongly rejects the hypothesis that human and physical capital differences create the main part of the income gap. As Hall and Jones (1999) do, he concludes that TFP can explain a large fraction of the differences. This means in our opinion that workers with different background become more productive, once the economic environment is set up in the proper way. We use his findings to explain the effect of FDI on Transition Economies. Working for MNCs is nearly the same as migrating to a very developed country. Workers use their own human capital and additionally can use a higher capital stock. Moreover, an advanced technology is applied, thus factors are used efficiently. The MNC endows the intermediate good supplier with the newest technology and enforces quality controls which improves the TFP. Smarzynska Javorcik (2004) states 
that the endowment of skilled labor in Transition Economies makes them good candidates for productivity spillovers to take place. The Barro and Lee (2000) database shows that education levels in EU Transition Economies are quite similar to those in Western Europe. Therefore, we cannot follow the approach of Acemoglu and Zilibotti (2001) who study productivity gaps between developed countries and less developed countries and attribute the differences to a technology-skill mismatch. We focus on technological spillovers and skill-biased technological change which makes skilled labor more productive ${ }^{3}$.

\subsubsection{Empirical productivity of skilled and unskilled labor in Poland}

Before moving to the model, we look at empirical data to see how the technological change evolves. Combining equation (2.3) with (2.7) we get the unobserved technology:

$$
\begin{gathered}
A \phi=\frac{y^{1 /(1-\alpha)} k^{-\alpha /(1-\alpha)}}{u l}\left(\frac{w_{l} u l}{w_{l} u l+w_{h}(1-u) h}\right)^{1 / \sigma} \\
A(1-\phi)=\frac{y^{1 /(1-\alpha)} k^{-\alpha /(1-\alpha)}}{(1-u) h}\left(\frac{w_{h}(1-u) h}{w_{l} u l+w_{h}(1-u) h}\right)^{1 / \sigma}
\end{gathered}
$$

Having data on $y, k, u, l, h, w_{l}$ and $w_{h}$, we calculate $A \phi$ and $A(1-\phi)$. A simple method to obtain $\phi$ from empirical data is to rewrite the skill premium equation (2.7):

$$
\frac{1-\phi}{\phi}=\left(\frac{w_{h}}{w_{l}}\right)^{1 / \sigma}\left(\frac{1-u h}{u} \frac{h}{l}\right)^{(1-\sigma) / \sigma}
$$

We observe the right hand side variables $u, h, l$, only need to make an assumption on the elasticity of substitution. Following Caselli and Coleman (2006) we set it to 1.4, thus $\sigma=0.285$. The exercise is repeated with other values for the elasticity, ranging in the interval $(1,2)$ as proposed by Autor, Katz and Krueger (1998). The parameter $\sigma$ is exogenous, and once fixed it remains constant. Call the right hand side $D$, thus $(1-\phi) / \phi=D$. Solving for $\phi$ we get $\phi=\frac{1}{1+D}$, which is:

$$
\phi=\frac{1}{1+\left(\frac{w_{h}}{w_{l}}\right)^{1 / \sigma}\left(\frac{1-u}{u} \frac{h}{l}\right)^{(1-\sigma) / \sigma}}
$$

\footnotetext{
${ }^{3}$ Another way to think about $\phi$ is the "erosion effect" proposed by Galor and Moav (2000). New technology makes some of the old skills obsolete. Skilled workers are able to to exploit technological change better than unskilled ones. Due to technological change the skilled workers become more productive, while unskilled workers loose productivity.
} 
Using empirical data for Poland ${ }^{4}$ we calculate the time-series for $\phi$. The data start in 1996 and the most recent value is from 2006. We consider only full-time workers employed in the private sector. This allows to look at a perfectly competitive labor market. Moreover, factors which might affect part-time workers and their wages are explicitly excluded. In total we have average wages for around 3-4 million workers. Workers are divided into five classes of education levels: tertiary (1), post-secondary (2), vocational secondary (3), general secondary (4) and primary (5). The development of the productivity of unskilled workers is presented under different definitions of skilled workers. First, we consider workers with tertiary or post-secondary education as skilled and try different values of the elasticity of substitution. The ratio between skilled/unskilled employed workers, the skill premium and the skill-biased technology parameter $\phi$ is presented in the following table.

\begin{tabular}{r|rrrrr}
\hline \hline & $1,2-3,4,5$ & & $\sigma=0.285$ & $\sigma=0.4$ & $\sigma=0.5$ \\
Year & $(1-u) h / u l$ & $w_{h} / w_{l}$ & $\phi$ & $\phi$ & $\phi$ \\
\hline 1996 & 0.544 & 1.505 & 0.523 & 0.473 & 0.448 \\
1998 & 0.575 & 1.557 & 0.458 & 0.431 & 0.417 \\
1999 & 0.646 & 1.636 & 0.348 & 0.360 & 0.367 \\
2001 & 0.799 & 1.691 & 0.218 & 0.274 & 0.304 \\
2002 & 0.828 & 1.704 & 0.198 & 0.259 & 0.294 \\
2004 & 0.930 & 1.719 & 0.152 & 0.224 & 0.267 \\
2006 & 0.997 & 1.905 & 0.095 & 0.167 & 0.217
\end{tabular}

Table 2.1: Development of skilled/unskilled labor supply, skill-premium and $\phi$, private sector.

There seems to be a rise in the proportion of skilled workers as well as in the skill premium, which is accompanied by a decline in unskilled technology. We also use other definitions of skilled workers.

\begin{tabular}{r|rrr||rrr}
\hline \hline & $1,2,3,4-5$ & & & $1-2,3,4,5$ & & \\
Year & $(1-u) h / u l$ & $w_{h} / w_{l}$ & $\phi$ & $(1-u) h / u l$ & $w_{h} / w_{l}$ & $\phi$ \\
\hline 1996 & 4.752 & 1.278 & 0.114 & 0.092 & 2.215 & 0.690 \\
1998 & 5.335 & 1.315 & 0.098 & 0.098 & 2.397 & 0.639 \\
1999 & 5.886 & 1.398 & 0.080 & 0.113 & 2.486 & 0.588 \\
2001 & 7.319 & 1.482 & 0.059 & 0.155 & 2.434 & 0.521 \\
2002 & 8.133 & 1.505 & 0.052 & 0.166 & 2.441 & 0.503 \\
2004 & 10.593 & 1.473 & 0.042 & 0.205 & 2.333 & 0.473 \\
2006 & 11.733 & 1.400 & 0.042 & 0.237 & 2.413 & 0.420
\end{tabular}

Table 2.2: Development of skilled/unskilled labor supply, skill-premium and $\phi$ under $\sigma=0.5$, for two different definitions of skilled/unskilled workers, private sector.

The left side of the table 2.2 presents results under the assumption that all workers but

\footnotetext{
${ }^{4}$ We obtain the longest time series among the considered countries from the Polish Central Statistical Office (2007) of Poland, therefore we present its case. For the other countries data is present since 2004 only.
} 
those with basic education (level 5) are skilled. The right side of the table shows another extreme that regards only those with tertiary education (level 1) as skilled. The elasticity is set equal to 2 , thus $\sigma=0.5$. To perform the calibration and be able to apply the results of the current literature, we chose the skill definition such that $u$ is 0.5 on average. Workers with general secondary education and below (levels 4,5) are considered as unskilled. Workers with at least vocational education (levels 1,2,3) are considered as skilled. Moreover, we look at the whole economy, because then the data on wages and the data on economically active people (from which we calculate $u$ ) can be easily connected. Both origin from the same source, namely the Polish Central Statistical Office (2007). Here $u$ is the share of unskilled workers in the total economically active population. $h$ and $l$ are calculated as the number of full-time employed workers divided by the economically active population in a given category. Thus, only full-time employed workers are considered as employed. The results under different elasticities are presented in table 2.3.

\begin{tabular}{r|rrr||rr}
\hline \hline & $1,2,3-4,5$ & & & $\sigma=0.4$ & $\sigma=0.5$ \\
Year & $(1-u) h / u l$ & $w=w_{h} / w_{l}$ & $u$ & $\phi$ & $\phi$ \\
\hline 1996 & 1.086 & 1.288 & 0.559 & 0.319 & 0.357 \\
1998 & 1.242 & 1.380 & 0.537 & 0.244 & 0.297 \\
1999 & 1.339 & 1.422 & 0.503 & 0.211 & 0.270 \\
2001 & 1.586 & 1.479 & 0.509 & 0.158 & 0.224 \\
2002 & 1.622 & 1.518 & 0.497 & 0.146 & 0.211 \\
2004 & 1.860 & 1.614 & 0.462 & 0.106 & 0.171 \\
2006 & 1.982 & 1.564 & 0.419 & 0.105 & 0.171
\end{tabular}

Table 2.3: Development of skilled/unskilled labor supply, wage and $\phi$ under $\sigma=0.4$ and 0.5 , whole economy.

Empirical data confirms the presence of skill-biased technological change in Poland. We apply the same approach to the most developed economy, namely the US. This allows us to state that the observation for Poland is in line with the general development in advanced economies and is not an exception.

\subsubsection{SBTC in the US}

We calculate the productivity of unskilled workers for the US over the period 1975-2008. The data ${ }^{5}$ origins from the US Bureau of Labour Statistics (2008). The education attainment levels are (1) college graduates, (2) less than a bachelor's degree, (3) high school graduates, no college and (4) less than a high school diploma. Wages are the median wages for the whole population. To calculate $\phi$ with equation (2.11), we apply an elasticity of substitution of 2, as in the case of Poland. Workers with education attainment levels

\footnotetext{
${ }^{5}$ Recent data can be found on http://www.bls.gov/cps/earnings.htm\#education, older data need to be requested by email.
} 
3 and 4 are considered as unskilled. The data on SBTC shows the following pattern. In 1975 the productivity of unskilled workers was 0.45 and declined nearly in a linear way until 1993 to take a value of 0.22. From there on SBTC can still be observed, however the decline of $\phi$ is much lower. The productivity of unskilled workers takes the value of 0.21 in 2000 and declines to 0.18 in 2008 . For the period 2000-2008 the data confirm a skill-biased technological change, which is less strong than in the case of Poland. It is quite difficult to literary compare the data because the definitions of skilled and unskilled workers are not identical. However, the relative productivity of skilled workers in both countries seems to be on a similar level, starting from 2000. This might indicate that Poland has undergone a strong SBTC and its production technology is adopted to the world technology frontier, which is represented by the US.

Moreover, data availability allows us to look at the share of skilled workers in the labor force for the period 1992-2008. The share of unskilled workers $u$ in 1992 is is 0.48, 0.42 in 2000 and decreases continuously, reaching 0.38 in 2008. As in Poland, an upgrading of skills can be observed. It is important to explain why workers decide to invest in education, but this is beyond the scope of the paper. The change in $u$ is considered as strictly exogenous.

\subsection{The households}

The household consist of skilled and unskilled workers and maximizes the total utility of its members. Utility comes from aggregate consumption and from leisure of both types of workers. We model the household side similar to Prasad (1996). Income is equally divided between skilled and unskilled households ${ }^{6}$. This assumption is necessary in order to keep the model simple and understandable. Workers can work only a fixed and given amount of hours, but they can choose the probability with which they supply labor. By law of large numbers we transform the probabilities into fractions of time devoted to work. Following the real business cycle literature, one week consists of 100 hours in which a worker can supply his laborforce (see for example Prescott (2004)). People tend to work around 40-50 hours a week. When the average hours are multiplied by the probability to work and transformed into a fraction of the 100 hours week, I get values for $h$ and $l$ which lie in the range of around 0.3 to 0.5 . In the model workers are endowed with one unit of time. As discussed in section 2.1 the unskilled worker devotes a fraction of time

\footnotetext{
${ }^{6}$ This is a very strong and counterfactual assumption. Significant income differences between skilled and unskilled households can be observed in the Transition Economies. Both kinds of households are separated and only a small fraction of the skilled income is transferred to the unskilled households. For the point that we make in this paper our simplified assumption is appropriate. The discussion on how to transfer consumption between two types of households would add another decision variable, which would affect the decision on how much to work.
} 
$0<l<1$ to work and the residual $1-l$ to leisure, thus labour supply and leisure add up to 1. Moreover, the skilled worker takes the same decision and devotes a fraction $0<h<1$ of his time to work and the residual time to leisure $1-h$. The constraint $l+(1-l)=1$ and $h+(1-h)=1$ always holds, thus workers use all available time. Further on, the household consists of a fraction $u$ of unskilled workers and a fraction $(1-u)$ of skilled workers. Each type of worker can decide independently of the other type's decision, how much labour to supply. The household's utility function is given by

$$
U(c, 1-l, 1-h)=\ln c+B \psi u \ln (1-l)+B(1-\psi)(1-u) \ln (1-h)
$$

Here $B$ is the weight on utility from leisure compared to consumption. $\psi$ determines how much weight is put on the utility of unskilled and skilled workers. The individuals are born as skilled or unskilled workers. The considered time period is too short to study endogenous education choice and we assume that $u$ can change but is exogenously given ${ }^{7}$. We suppress the time index from now on. The size of the household grows with the rate $n$ and the subjective rate of time preferences is denoted by $\rho$. The household maximizes the discounted stream of utility: $\max _{c, l, h} \int_{t=0}^{\infty} e^{-(\rho-n) t} U(c, 1-l, 1-h) d t$ and has to obey the budget constraint:

$$
\dot{k}=w_{l} u l+w_{h}(1-u) h+r k-(\delta+n) k-c
$$

We set up the Hamiltonian and solve it:

$$
\begin{gathered}
H: \quad e^{-(\rho-n) t}[\ln c+B \psi u \ln (1-l)+B(1-\psi)(1-u) \ln (1-h)] \\
+\lambda\left[w_{l} u l+w_{h}(1-u) h+r k-(\delta+n) k-c\right] \\
\frac{\partial H}{\partial c}=0 \Leftrightarrow \quad e^{-(\rho-n) t} \frac{1}{c}=\lambda \\
\frac{\partial H}{\partial l}=0 \Leftrightarrow \quad e^{-(\rho-n) t} \frac{B \psi u}{1-l}=\lambda w_{l} u \\
\frac{\partial H}{\partial h}=0 \Leftrightarrow \quad e^{-(\rho-n) t} \frac{B(1-\psi)(1-u)}{1-h}=\lambda w_{h}(1-u) \\
\frac{\partial H}{\partial k}=-\dot{\lambda} \Leftrightarrow \quad r-\delta-n=-\frac{\dot{\lambda}}{\lambda} \\
\text { TVC } \quad \lim _{t \rightarrow \infty} e^{-(\rho-n) t} c^{-1} k=0
\end{gathered}
$$

\footnotetext{
${ }^{7}$ Basing on data of the International Labor Organization (2008) http://laborsta.ilo.org, the annual average growth rate of the labor-force share with secondary and tertiary education was 0.5 and 0.43 percentage points over the period 1996-2005, for the Czech Republic, Hungary, Poland, the Slovak Republic and Slovenia.
} 
After log-linearization of equation (2.15) and substitution in equation (2.18) we get the Euler equation

$$
\frac{\dot{c}}{c}=r-\delta-\rho
$$

Now we combine equation (2.15) and (2.16)

$$
\frac{B \psi}{1-l} \frac{1}{w_{l}}=\frac{1}{c}
$$

and equation (2.15) and (2.17)

$$
\frac{B(1-\psi)}{1-h} \frac{1}{w_{h}}=\frac{1}{c}
$$

Moreover, we combine equation (2.21) and (2.22),

$$
\frac{B \psi}{1-l} \frac{1}{w_{l}}=\frac{B(1-\psi)}{1-h} \frac{1}{w_{h}}
$$

which after rewriting leads to the optimal allocation of leisure.

$$
\frac{w_{h}}{w_{l}}=\frac{1-\psi}{\psi} \frac{1-l}{1-h}
$$

From the firms sector we know the skill premium (2.7) and plug it into equation (2.24)

$$
\frac{1-\psi}{\psi} \frac{1-l}{1-h}=\left(\frac{1-\phi}{\phi}\right)^{\sigma}\left(\frac{1-u h}{u} \frac{h}{l}\right)^{\sigma-1}
$$

We rewrite it to obtain the optimal labor ratio for both kinds of workers.

$$
\frac{1-\psi}{\psi}\left(\frac{1-\phi}{\phi}\right)^{-\sigma}\left(\frac{1-u}{u}\right)^{1-\sigma}=\frac{1-h}{1-l}\left(\frac{h}{l}\right)^{\sigma-1}
$$

A comparative statics analysis of the equilibrium is performed in Appendix A.1. In the next step we include exogenous neutral technological change.

\subsubsection{Equilibrium with SBTC and TFP growth}

In order to introduce neutral technological change into the model, we modify the production function. Throughout the paper SBTC and TFP growth are strictly exogenous. Appendix A.2 gives an insight, how the changes can be endogenized and linked to FDI. Exogenous neutral technological change (TFP growth) is denoted as $\dot{A} / A=g$. We start from $A=A_{0} e^{g t}$. $A_{0}$ can be normalized to 1 , thus in any point in time $A=e^{g t}$. Dividing the variables $y, k$ and $c$ by $A$ leads to variables in per-efficient-labor units. Now, output 
is called $\tilde{y}=y / A$, capital $\tilde{k}=k / A$ and consumption $\tilde{c}=c / A$. The production function thus becomes $\tilde{y}=\tilde{k}^{\alpha}\left[(\phi u l)^{\sigma}+((1-\phi)(1-u) h)^{\sigma}\right]^{(1-\alpha) / \sigma}$. After profit maximization, thus differentiation with respect to the inputs $u l,(1-u) h$ and $\tilde{k}$, we obtain:

$$
\begin{gathered}
\tilde{w}_{l}=(1-\alpha) \tilde{k}^{\alpha}\left[(\phi u l)^{\sigma}+((1-\phi)(1-u) h)^{\sigma}\right]^{(1-\alpha) / \sigma-1} \phi^{\sigma}(u l)^{\sigma-1} \\
\tilde{w}_{h}=(1-\alpha) \tilde{k}^{\alpha}\left[(\phi u l)^{\sigma}+((1-\phi)(1-u) h)^{\sigma}\right]^{(1-\alpha) / \sigma-1}(1-\phi)^{\sigma}((1-u) h)^{\sigma-1} \\
\tilde{r}=\alpha \tilde{k}^{\alpha-1}\left[(\phi u l)^{\sigma}+((1-\phi)(1-u) h)^{\sigma}\right]^{(1-\alpha) / \sigma}
\end{gathered}
$$

The budget constraint written in per efficient labor unit terms becomes $y / A=c / A+\dot{k} / A+$ $(n+\delta) k / A$. We use $\dot{\tilde{k}}=(k \dot{/ A})=\dot{k} / A-k \dot{A} / A^{2}$, plug it into the budget constraint and obtain after some rewriting

$$
\dot{\tilde{k}}=\tilde{w}_{l} u l+\tilde{w}_{h}(1-u) h+r \tilde{k}-(\boldsymbol{\delta}+n+g) \tilde{k}-\tilde{c}
$$

The control variable, consumption, is measured in per efficiency units, however the agents are interested in per capita consumption. This has to be considered in the utility function. Knowing that $c=\tilde{c} A=\tilde{c} e^{g t}$, the objective function becomes: $\max _{\tilde{c}, l, h} \int_{t=0}^{\infty} e^{-(\rho-n) t} U\left(\tilde{c} e^{g t}, 1-\right.$ $l, 1-h) d t$. We set up the Hamiltonian and solve it as described above.

$$
\begin{array}{r}
H: \quad e^{-(\rho-n) t}\left[\ln \left(\tilde{c} e^{g t}\right)+B \psi u \ln (1-l)+B(1-\psi)(1-u) \ln (1-h)\right] \\
+\lambda\left[\tilde{w}_{l} u l+\tilde{w}_{h}(1-u) h+r \tilde{k}-(\delta+n+g) \tilde{k}-\tilde{c}\right]
\end{array}
$$

The resulting Euler equation is

$$
\frac{\dot{\tilde{c}}}{\tilde{c}}=r-\delta-\rho-g
$$

and as before,

$$
\frac{B \psi}{1-l} \frac{1}{\tilde{w}_{l}}=\frac{1}{\tilde{c}} \quad \text { and } \quad \frac{B(1-\psi)}{1-h} \frac{1}{\tilde{w}_{h}}=\frac{1}{\tilde{c}}
$$

describe the intra-temporal substitution between labor and consumption. Together with the TVC the unique optimal behaviour in equilibrium is described. If $g=0$, the model is exactly as before, since then $A=1$ in all periods. We are interested in the case $g>0$. In order to obtain the values of $k$ and $c$ in per capita terms, $\tilde{k}$ and $\tilde{c}$ have to be multiplied by $A$, which grows over time.

We found how firms and households behave in equilibrium and now move on to study the impact of a change in $\phi$ on skilled and unskilled labor and physical capital demand in equilibrium. 


\section{Calibration and numerical analysis of the equilibrium}

We calibrate the model basing on empirical data and test whether it is consistent with empirical observations. Lack of empirical data for a longer period makes an empirical analysis infeasible ${ }^{8}$. Thus, we calculate the unobserved parameter $\phi$ using the previously presented method and calibrate the model. We perform comparative statics, namely fix the TFP and study the equilibrium under different $\phi$ values. The economy in equilibrium is described by seven equations with seven unknown variables. The variables of interest are: $k, c, h, l, w_{h}, w_{l}$ and $r$. The equations are the optimality conditions in the firm sector (equations (2.4)-(2.6)), the budget constraint (2.13) and the Euler equation (2.20), and finally the substitution of marginal utility from leisure and consumption $((2.21)$ and (2.22)). The capital share is set to $\alpha=0.35$. The elasticity of substitution is set to 2 $(\sigma=0.5)$. The TFP $A$ is arbitrarily set to 1 , as it only scales up $k, c, w_{h}$ and $w_{l}$, but has no effect on $h$ and $l$. Moreover, $u$ is set to 0.509, a value observed in 2001 for Poland. Still we need to calibrate $B, \psi, \delta$ and $\rho$. The rate of time preferences can be set as 0.065 (see Benhabib and Perli (1994) and Benhabib and Farmer (1994)) and the depreciation of physical capital lies in the range 0.06-0.1 (see King and Rebelo (1999) and Stokey and Rebelo (1995)). We set $\delta=0.06$.

First, we apply empirical data to equation 2.24 and get $\psi$. The relative weight of the utility of unskilled workers in total utility of the household is calibrated as $\psi=0.46$. This value is in line with Prasad's specification, who sets it equal to 0.4. The parameter $B$ is set to match equations (2.21) and (2.22) with empirical data and the procedure is as follows. In equilibrium $\dot{c}=0$ holds, thus $r=\delta+\rho$. We apply this fact and the observed $h$ and $l$ for different $\phi$ values from table 2.3 to the interest rate equation (2.6) and find $k^{*}$. Now plug $k^{*}$ into $\dot{k}=0$ to find $c^{*}$. Applying $c^{*}$ to equations (2.21) and (2.22) results in $B=2.12783$. Moreover, we use the previously calibrated values to find the wages $w_{l}$ and $w_{h}$.

Using the calibrated parameters $\sigma, \psi, B, \alpha, \delta$ and $\rho$, which are kept fixed, the seven equations with seven unknowns are solved numerically. This procedure is repeated for $\phi$ in the range $0.15-0.45$, where $\phi$ decreases by very small values. We obtain a monotone function for the variables $k, h, l, c$ and $w_{l}$ and plot it. Only $w_{h}$ shows a maximum at $\phi=$ 0,22 . The exercise is performed with steps of size 0.0001 . Table 3.1 presents the results using steps of 0.01 . The variables in equilibrium are presented in the following graph 3.1 , the variable $k$ is omitted to improve legibility. In equilibrium, the variables behave as

\footnotetext{
${ }^{8}$ In case enough empirical data becomes available, the TFP time series can be calculated using equation $A=y^{1 /(1-\alpha)} k^{\alpha /(\alpha-1)}\left[(\phi u l)^{\sigma}+((1-\phi)(1-u) h)^{\sigma}\right]^{-1 / \sigma}$. TFP growth can be endogenized, as presented in Appendix A.2. In the next step, equation (A.6) which describes its growth can be estimated. Moreover, the equation (A.5) which describes the change of $\phi$ with the increase of foreign owned capital stock in the economy can be estimated as well.
} 
predicted $^{9}$ by the analysis on $d l / d \phi, d h / d \phi$ and $d k / d \phi$ in appendix A.1. Increasing the productivity of the skilled workers and decreasing that of the unskilled workers results in a higher $h$ and lower $l$ as well as in an increased skill-premium. We also observe a decline in $k$ and $c$, which indicates a decline in welfare. This is only due to the fact that TFP is kept constant. SBTC decreases the productivity of unskilled workers more than it increases that of skilled workers, in relative terms (e.g. a change from $\phi=0.2$ and $1-\phi=$ 0.8 by 0.01 means an decrease of $5 \%$ and an increase of $1.25 \%$ ).

\begin{tabular}{l|llllll}
\hline \hline$\phi$ & $k$ & $h$ & $l$ & $w_{h}$ & $w_{l}$ & $c$ \\
\hline \hline 0.44 & 2.0562 & 0.421487 & 0.425786 & 1.20168 & 1.0534 & 0.610986 \\
0.43 & 2.05336 & 0.42476 & 0.42208 & 1.20685 & 1.0452 & 0.610142 \\
0.42 & 2.05017 & 0.428009 & 0.418311 & 1.21182 & 1.03681 & 0.609193 \\
0.41 & 2.04662 & 0.431236 & 0.414474 & 1.21658 & 1.02823 & 0.608137 \\
0.4 & 2.0427 & 0.434444 & 0.410566 & 1.22114 & 1.01946 & 0.606974 \\
0.39 & 2.03842 & 0.437634 & 0.406583 & 1.22549 & 1.0105 & 0.605701 \\
0.38 & 2.03377 & 0.440808 & 0.40252 & 1.22963 & 1.00133 & 0.604319 \\
0.37 & 2.02874 & 0.443967 & 0.398372 & 1.23357 & 0.991973 & 0.602826 \\
0.36 & 2.02333 & 0.447114 & 0.394135 & 1.23728 & 0.98241 & 0.601219 \\
0.35 & 2.01754 & 0.450251 & 0.389802 & 1.24078 & 0.972642 & 0.599498 \\
0.34 & 2.01136 & 0.45338 & 0.385369 & 1.24405 & 0.962666 & 0.597661 \\
0.33 & 2.00477 & 0.456501 & 0.380828 & 1.2471 & 0.952479 & 0.595704 \\
0.32 & 1.99778 & 0.459619 & 0.376173 & 1.24992 & 0.942074 & 0.593627 \\
0.31 & 1.99038 & 0.462733 & 0.371397 & 1.25251 & 0.93145 & 0.591426 \\
0.3 & 1.98254 & 0.465847 & 0.36649 & 1.25485 & 0.920599 & 0.589099 \\
0.29 & 1.97428 & 0.468962 & 0.361446 & 1.25695 & 0.909518 & 0.586642 \\
0.28 & 1.96556 & 0.472081 & 0.356253 & 1.2588 & 0.898201 & 0.584054 \\
0.27 & 1.95639 & 0.475205 & 0.350902 & 1.26038 & 0.88664 & 0.581329 \\
0.26 & 1.94675 & 0.478338 & 0.345381 & 1.2617 & 0.874829 & 0.578464 \\
0.25 & 1.93663 & 0.481482 & 0.339676 & 1.26275 & 0.862761 & 0.575455 \\
0.24 & 1.926 & 0.484638 & 0.333775 & 1.26351 & 0.850426 & 0.572297 \\
0.23 & 1.91485 & 0.487811 & 0.327662 & 1.26398 & 0.837816 & 0.568985 \\
0.22 & 1.90317 & 0.491003 & 0.321318 & 1.26415 & 0.824921 & 0.565513 \\
0.21 & 1.89092 & 0.494217 & 0.314726 & 1.264 & 0.811729 & 0.561875 \\
0.2 & 1.8781 & 0.497456 & 0.307861 & 1.26352 & 0.798228 & 0.558064 \\
0.19 & 1.86467 & 0.500725 & 0.300701 & 1.26269 & 0.784404 & 0.554072 \\
0.18 & 1.8506 & 0.504027 & 0.293218 & 1.26151 & 0.770242 & 0.549891 \\
0.17 & 1.83586 & 0.507367 & 0.285378 & 1.25994 & 0.755725 & 0.545512 \\
0.16 & 1.82041 & 0.510749 & 0.277146 & 1.25798 & 0.740833 & 0.540923 \\
0.15 & 1.80422 & 0.51418 & 0.26848 & 1.2556 & 0.725546 & 0.536112 \\
& & & & & & \\
& & & & & &
\end{tabular}

Table 3.1: Values of $k, h, l, w_{h}, w_{l}$ and $c$, in equilibrium, under fixed $A=1$.

We keep $u=0.509$ constant, thus the population consists of more unskilled than skilled workers. Consequently, under the above setting, SBTC decreases the output in equilibrium if it is not accompanied by a TFP growth. The calculated values of $l$ and $h$ cannot

\footnotetext{
${ }^{9}$ Comparing the results of the two different approaches, we have to bear in mind that in the above analysis the ratio between $h$ and $l$ changes over time. However, it is fixed for simplicity when we perform the comparative statics analysis in appendix A.1.
} 
be interpreted literary as employment, because we take only fully employed workers into account. Part-time workers are considered as unemployed in this analysis. We assume that part-time workers react in a similar way to SBTC as full-time employed ones do. The conclusions that we draw under this settings apply to the whole economy.

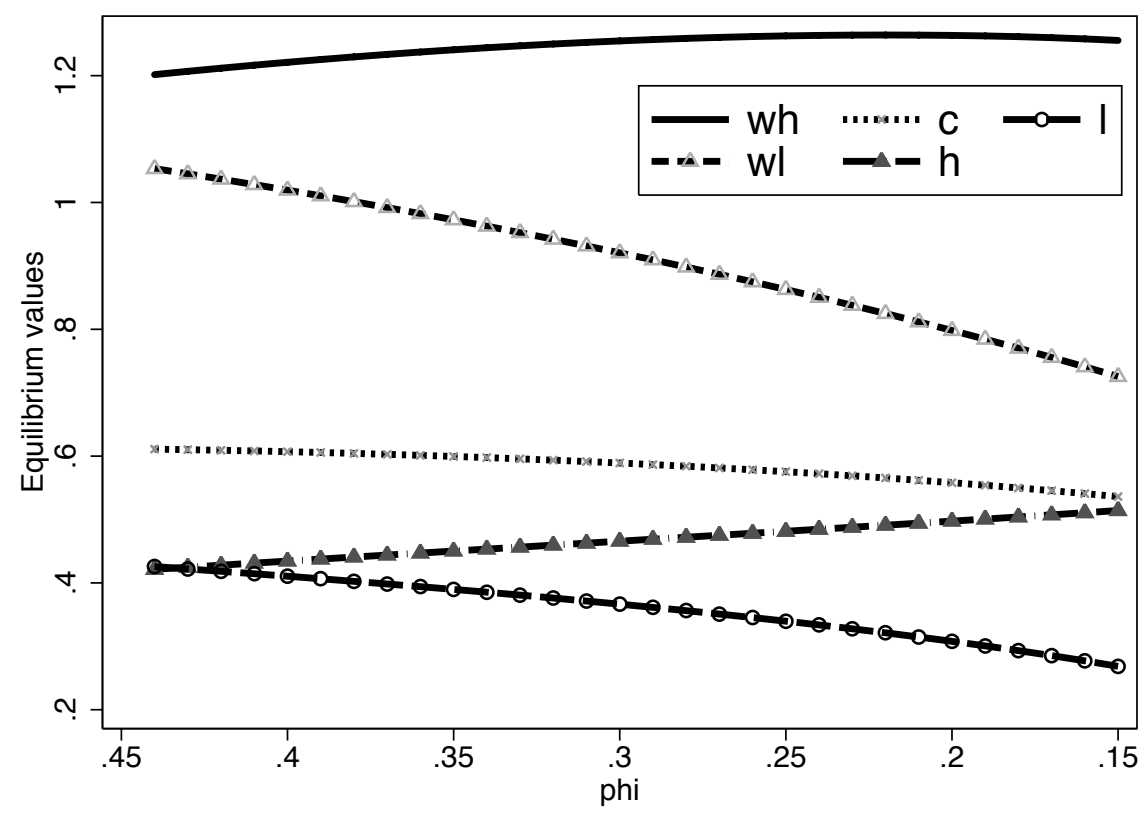

Figure 3.1: Equilibrium values for $w_{h}, w_{l}, c, h$ and $l$ (top to bottom) under skill-biased technological change, thus for decreasing $\phi$ values.

We now allow $A$ to increase when $\phi$ decreases ${ }^{10}$. Explicitly, we connect a 0.01 decline in $\phi$ with an increase in $A$ of $2 \%$, starting from $\phi=0.44$ and $A=1$. Another way to look at this is to consider SBTC as a linear process of time. This is a very strong simplification, however makes the analysis significantly easier and the results more transparent. From empirical studies we know that exogenous TFP growth can be set to around $2 \%$ per year. The parameter $B$ needs to be calibrated again. It is calibrated now as $B=2.19403$ and is slightly higher than before. As workers become more productive, they need to spend less time in the production process, keeping the output constant. If they are aware of the constant productivity growth they value leisure a little bit more than they would if no technological progress were present. Under this setting a decrease of $\phi$ leads to a higher employment of the skilled workers, lower employment of the unskilled workers, a higher capital stock and consumption. Thus the welfare of everybody increases. This result is presented in table 3.2 and shown in graph 3.2. The economy grows if SBTC

\footnotetext{
${ }^{10}$ This can be motivated with the assumption that skilled workers adopt the higher TFP level of most developed economies. Skill-biased technological change increases $h$ and as a by-product, a higher TFP is adopted.
} 
is accompanied by a sufficiently high TFP growth. The effect of international knowledge spillovers is therefore positive for the economy, if there is a balance between the improvement of TFP and better usage of skilled workers.

\begin{tabular}{l|llllll}
\hline \hline$\phi$ & $k$ & $h$ & $l$ & $w_{h}$ & $w_{l}$ & $c$ \\
\hline \hline 0.44 & 1.63643 & 0.421483 & 0.425787 & 1.10938 & 0.972488 & 0.547036 \\
0.43 & 1.66718 & 0.424756 & 0.422081 & 1.13667 & 0.984408 & 0.557315 \\
0.42 & 1.69822 & 0.428005 & 0.418312 & 1.1644 & 0.996235 & 0.567689 \\
0.41 & 1.72952 & 0.431232 & 0.414475 & 1.19259 & 1.007955 & 0.578156 \\
0.4 & 1.76108 & 0.43444 & 0.410567 & 1.22125 & 1.019544 & 0.588706 \\
0.39 & 1.7929 & 0.43763 & 0.406584 & 1.25036 & 1.030989 & 0.599338 \\
0.38 & 1.82495 & 0.440803 & 0.40252 & 1.27993 & 1.042284 & 0.610053 \\
0.37 & 1.8572 & 0.443963 & 0.398373 & 1.30995 & 1.053392 & 0.620835 \\
0.36 & 1.88967 & 0.44711 & 0.394135 & 1.34044 & 1.064315 & 0.63169 \\
0.35 & 1.92233 & 0.450247 & 0.389803 & 1.37139 & 1.075022 & 0.642608 \\
0.34 & 1.95514 & 0.453376 & 0.38537 & 1.40278 & 1.085486 & 0.653577 \\
0.33 & 1.98812 & 0.456497 & 0.380829 & 1.43464 & 1.095699 & 0.664601 \\
0.32 & 2.02121 & 0.459614 & 0.376174 & 1.46692 & 1.105621 & 0.67566 \\
0.31 & 2.05439 & 0.462729 & 0.371397 & 1.49965 & 1.115235 & 0.686754 \\
0.3 & 2.08765 & 0.465843 & 0.366491 & 1.53281 & 1.124511 & 0.69787 \\
0.29 & 2.12094 & 0.468958 & 0.361447 & 1.56639 & 1.133419 & 0.709 \\
0.28 & 2.15424 & 0.472077 & 0.356254 & 1.60038 & 1.141929 & 0.720132 \\
0.27 & 2.18751 & 0.475201 & 0.350903 & 1.63477 & 1.150002 & 0.731251 \\
0.26 & 2.2207 & 0.478334 & 0.345381 & 1.66954 & 1.157603 & 0.742346 \\
0.25 & 2.25377 & 0.481478 & 0.339677 & 1.70467 & 1.164691 & 0.7534 \\
0.24 & 2.28668 & 0.484634 & 0.333776 & 1.74016 & 1.171232 & 0.764403 \\
0.23 & 2.31938 & 0.487807 & 0.327663 & 1.77598 & 1.177178 & 0.775332 \\
0.22 & 2.3518 & 0.490999 & 0.321319 & 1.81209 & 1.182477 & 0.786171 \\
0.21 & 2.38385 & 0.494213 & 0.314726 & 1.84847 & 1.187067 & 0.79689 \\
0.2 & 2.41552 & 0.497452 & 0.307862 & 1.8851 & 1.190905 & 0.807474 \\
0.19 & 2.4467 & 0.500721 & 0.300702 & 1.92193 & 1.193924 & 0.817895 \\
0.18 & 2.47729 & 0.504023 & 0.293218 & 1.95891 & 1.196055 & 0.828122 \\
0.17 & 2.50721 & 0.507363 & 0.285379 & 1.99601 & 1.197219 & 0.838123 \\
0.16 & 2.53634 & 0.510746 & 0.277147 & 2.03316 & 1.197334 & 0.847858 \\
0.15 & 2.56456 & 0.514176 & 0.268481 & 2.07031 & 1.196316 & 0.857296
\end{tabular}

Table 3.2: Values of $k, h, l, w_{h}, w_{l}$ and $c$, in equilibrium, under increasing $A$.

In our model the two households share consumption independent of their income. In the real economy unskilled workers are separated from the skilled ones. If their wage becomes relatively low they loose a lot of welfare. The state has to subsidize their consumption by taxing the richer skilled workers. The same or a higher welfare level can be only achieved if the GDP increases by a sufficient large amount to cover the loss perceived by the less skilled workers. We do not have enough data to link the SBTC to the education attainment choice of the workers. However the share of skilled workers increases in Poland as well as in the US. This indicates that workers understand the cause of the increasing wage gap and increase their education in order to improve their welfare. 


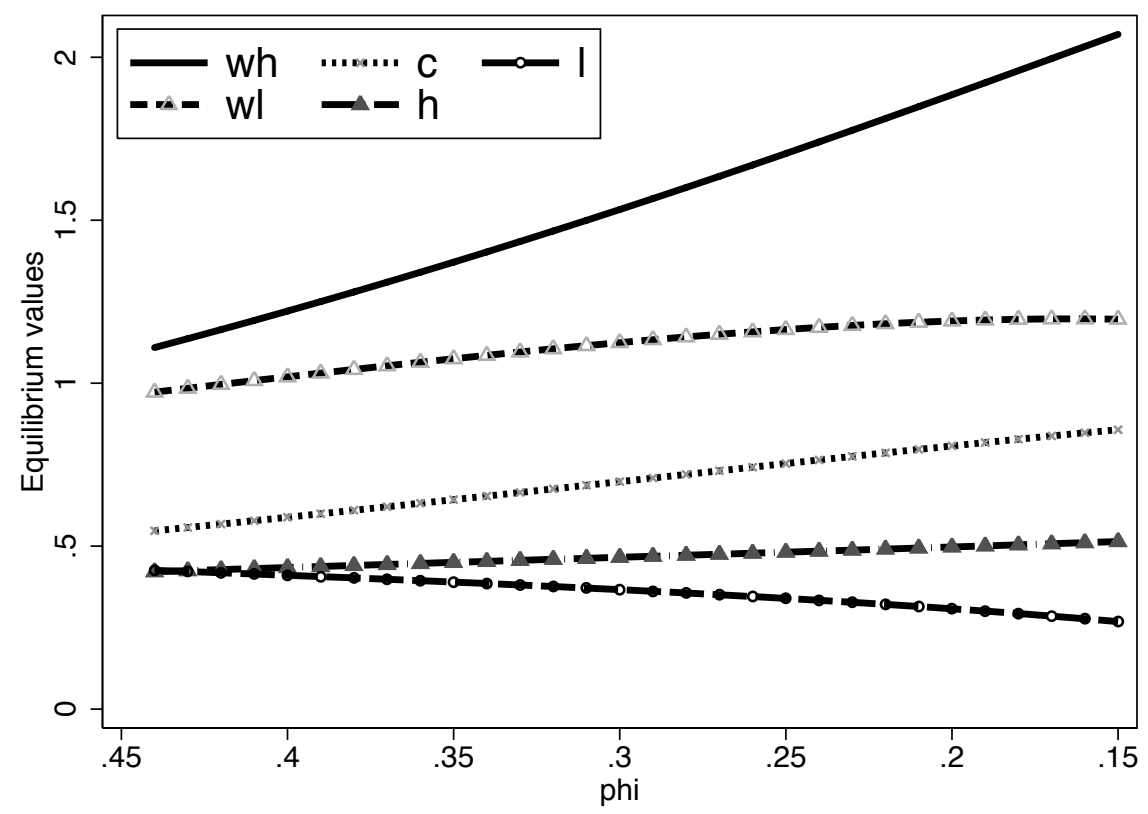

Figure 3.2: Equilibrium values for $w_{h}, w_{l}, c, h$ and $l$ (top to bottom) under skill-biased technological change, thus for decreasing $\phi$ values, under TFP growth.

Finally, we test the empirical relevance of the model. Fixing $A=1$ and using the same parameters as described above, we calculate the equilibrium for all observed years. We apply the productivity $\phi$ of unskilled workers and the share $u$ of unskilled workers in the active population that is actually observed in the given year. We calculate $\phi$ with equation 2.11 and data from the Polish Central Statistical Office (2007). Using this values, we calculate the value of $k, h, l, w_{h}, w_{l}$ and $c$ in equilibrium. We compare the calculated ratio of skilled to unskilled labor input $(1-u) h / u l$ and the wage inequality $w_{h} / w_{l}$ with its empirical value. The results are presented in table 3.3. The simulated values follow the empirical values quite well. However, differences can be observed. They origin from the assumption of perfect competitive equilibrium. The simulated value gives the agents' optimal behaviour in equilibrium, while the empirical data are just very close to the equilibrium. Employment laws, government interventions and other economic factors make the agents choose allocations that are not optimal. Moreover, our calibration bases on very few observations. Further on, we do not observe the real hours worked, but calculate $h$ as the share of full-time, skilled workers among all economically active skilled workers. The same applies to $l$. Part-time workers are completely neglected in this model. However, people do not jump between employment and unemployment, but rather choose steps in-between. As there is no other data available, we have to focus on full-time employment. 


\begin{tabular}{r|rrr||r||rr}
\hline \hline & observed & & & & simulated & \\
& $1,2,3-4,5$ & & & & & \\
Year & $(1-u) h / u l$ & $w=w_{h} / w_{l}$ & $u$ & $\phi$ & $(1-u) h / u l$ & $w=w_{h} / w_{l}$ \\
\hline 1996 & 1.086 & 1.288 & 0.559 & 0.357 & 0.982 & 1.354 \\
1998 & 1.242 & 1.380 & 0.537 & 0.297 & 1.168 & 1.424 \\
1999 & 1.339 & 1.422 & 0.503 & 0.270 & 1.338 & 1.421 \\
2001 & 1.586 & 1.479 & 0.509 & 0.224 & 1.473 & 1.534 \\
2002 & 1.622 & 1.518 & 0.497 & 0.211 & 1.569 & 1.544 \\
2004 & 1.860 & 1.614 & 0.462 & 0.171 & 1.927 & 1.586 \\
2006 & 1.982 & 1.564 & 0.419 & 0.171 & 2.127 & 1.510
\end{tabular}

Table 3.3: Simulated and observed development of skilled/unskilled labor supply and skillpremium under $\sigma=0.5$, whole economy, Poland.

The numerical analysis shows that the model is useful in explaining output growth and especially the increasing employment of skilled workers and unemployment of unskilled workers.

\subsection{Calibration for the US}

Calibrating the model to the US shows that it is also empirically relevant for the most advanced economy. The calibration is performed as in the case of Poland. Data on wages, employment and unemployment origins from the US Bureau of Labour Statistics (2008). We use the largest available time series, which covers the period 1992-2008. The elasticity of substitution is set equal to $2(\sigma=0.5)$ and the parameters that enter the utility function are calibrated as $\psi=0.3912$ and $B=2.4375$ to match empirical data. Those parameters are similar to those obtained for Poland. The weight of the utility of skilled workers in the total utility seems to be higher in the US. However, this can be affected by the definition of skilled workers. The workers in the US seem to put a higher weight on the utility from leisure compared to that from consumption than workers in Poland do. In advanced economies leisure becomes more valuable than consumption, possibly because of the very high consumption level and scarcity of leisure. The data shows a very high employment rate. We perform two tests on the relevance of the model. First, we calibrate the parameters basing on the whole sample. Using the parameters and observed technology $\phi$ we calculate the skill-premium and ratio of labor supply for the period 1999-2008. The observed and simulated values are presented in table 3.4. The simulated skill-premium is $0.5 \%$ lower while the labor supply of skilled workers relative to unskilled ones is $1.5 \%$ higher, on average. The second test is to calibrate the parameters for the period 19921998 and predict the development in the following period. In this case, the parameters are calibrated as $\psi=0.39518$ and $B=2.4681$. The average share of skilled workers in the labor force for the first period is $u=0.449$ and $u=0.401$ for the second. The simu- 
lated skill-premium is now by $1.5 \%$ lower than the observed one, on average. The labor supply of skilled to unskilled workers is by $3 \%$ higher. Considering the relatively small error, the model is useful in predicting the reaction of the labor market to a skill-biased technological change. It is crucial to include the appropriate share of unskilled workers in the population into the solution of the equilibrium. Policy makers can predict the shares of skilled workers quite well, as they observe the enrollment in schools and universities. Once the model is calibrated for a country, it is very useful in predicting the reaction of unskilled workers to SBTC. Policy makers can take appropriate actions in order to sustain the welfare of unskilled workers.

\begin{tabular}{|c|c|c|c|c|c|c|c|c|}
\hline year & $\begin{array}{l}\text { observed } \\
(1-u) h / u l\end{array}$ & $w_{h} / w_{l}$ & $u$ & $\phi$ & $\begin{array}{r}\text { simulated on } \\
1992-1998 \\
(1-u) h / u l \\
\end{array}$ & $w_{h} / w_{l}$ & $\begin{array}{l}\text { simulated on } \\
\text { full sample } \\
(1-u) h / u l\end{array}$ & $w_{h} / w_{l}$ \\
\hline 1999 & 1.397 & 1.594 & 0.422 & 0.220 & 1.433 & 1.574 & 1.412 & 1.586 \\
\hline 2000 & 1.419 & 1.598 & 0.418 & 0.216 & 1.437 & 1.588 & 1.437 & 1.588 \\
\hline 2001 & 1.447 & 1.600 & 0.414 & 0.212 & 1.477 & 1.598 & 1.465 & 1.598 \\
\hline 2002 & 1.469 & 1.598 & 0.411 & 0.210 & 1.507 & 1.578 & 1.484 & 1.590 \\
\hline 2003 & 1.498 & 1.582 & 0.406 & 0.211 & 1.499 & 1.581 & 1.499 & 1.581 \\
\hline 2004 & 1.526 & 1.573 & 0.402 & 0.209 & 1.520 & 1.577 & 1.520 & 1.577 \\
\hline 2005 & 1.535 & 1.585 & 0.400 & 0.206 & 1.541 & 1.584 & 1.541 & 1.584 \\
\hline 2006 & 1.560 & 1.599 & 0.396 & 0.201 & 1.603 & 1.577 & 1.578 & 1.589 \\
\hline 2007 & 1.629 & 1.622 & 0.385 & 0.189 & 1.672 & 1.601 & 1.672 & 1.601 \\
\hline 2008 & 1.673 & 1.628 & 0.380 & 0.184 & 1.744 & 1.594 & 1.717 & 1.606 \\
\hline
\end{tabular}

Table 3.4: Simulated and observed development of skilled/unskilled labor supply, and skillpremium under $\sigma=0.5$, US.

When we consider SBTC as an exogenous process the model can explain the formation of the skill-premium. The labor supply of skilled and unskilled workers in the US is very similar and stays constant over time. However, the share of unskilled workers decreases over time, from 0.48 in 1992 to 0.38 in 2008. A similar pattern can be observed in the case of Poland. There are too few data to run a proper regression on the link of SBTC and education attainment, however the data indicate that also in the US the increasing skill-premium makes education attractive.

\section{Conclusion}

This paper relates the change in the structure of the labor market and output growth observed in Central and Eastern European Transition Economies to technological change. We present a model which links skill-biased technological change with the labor market. Using elastic labor supply and skill-biased technological change we explain the observed increase of unemployment of unskilled workers. Calibration of the model to Polish and 
US data and numerical analysis shows its empirical relevance.

Contrary to the main stream of the SBTC literature we allow labor supply to be endogenous. We deal with a heterogeneous-agents model of economic growth and present numerical results. The major contribution of our model is that it explains the significant employment drop of unskilled workers in Transition Economies. This paper is the first attempt to present a complete model that explains the change of the labor market in Transition Economies with skill-biased technological change. The model allows to simulate the economy and study the effect of SBTC. If SBTC is not followed by a growth in total factor productivity, then the output, physical capital stock and consumption decline. However, SBTC in Transition Economies leads to a decrease of unskilled labor, increase of skilled labor, and also TFP grows. Consequently, the output increases. Our paper shows that in order to improve welfare, policy makers have to take care that an appropriate combination of SBTC and TFP growth takes place.

One possible extension is to consider both SBTC and TFP growth as an endogenous process which is driven by FDI. This allows to study the effect of an increase of FDI or a counterfactual development, assuming that no FDI was present at all. This should allow us to state how the economies would evolve without FDI. Consequently, we can assess the importance of FDI and its role in knowledge diffusion. Moreover, once a sufficient amount of empirical data is available, the model can be calibrated to one Transition Economy and applied to another one, or to onother highly developed OECD country to check its performance.

\section{A Appendix}

\section{A.1 Comparative statics - the impact of $\phi$ on $l, h$ and $k$}

In order to study the effect of a change in the parameter $\phi$ on unskilled and skilled labor demand and the physical capital stock, we take the total differential of the three firms' optimality conditions (2.4), (2.5) and (2.6). This approach follows Cieślik (2008). We know from the households optimality equation (2.24) that the supply of skilled and unskilled labor depends on the skill premium. After substituting the wage for skilled and unskilled labor and rewriting, we get equation (2.26), which I call $S$ :

$$
S=\frac{1-\psi}{\psi}\left(\frac{1-\phi}{\phi}\right)^{-\sigma}\left(\frac{1-u}{u}\right)^{1-\sigma}-\frac{1-h}{1-l}\left(\frac{h}{l}\right)^{\sigma-1}
$$

We use the following three equations which completely describe the economy: $S, w_{h}$ and $r$ and differentiate them with respect to $\phi, l, h$ and $k$. To simplify the notation, we use $w_{l}$, 
$w_{h}$ and $r$, and the second subscript denotes the first derivative with respect to the given parameter. In matrix notation we obtain:

$$
\left(\begin{array}{ccc}
S_{k} & S_{l} & S_{h} \\
w_{h k} & w_{h l} & w_{h h} \\
r_{k} & r_{l} & r_{h}
\end{array}\right)\left(\begin{array}{c}
d k \\
d l \\
d h
\end{array}\right)=\left(\begin{array}{c}
-S_{\phi} \\
-w_{h \phi} \\
-r_{\phi}
\end{array}\right) d \phi
$$

We solve this system of three linear equations for $d k, d l$ and $d h$, use the fact that $S_{k}=0$ and after rearranging the terms obtain the following expressions:

$$
\begin{gathered}
\frac{d l}{d \phi}=\frac{-w_{h k} S_{h} r_{\phi}+w_{h k} S_{\phi} r_{h}+S_{h} r_{k} w_{h \phi}-S_{\phi} r_{k} w_{h h}}{-w_{h k} S_{l} r_{h}+r_{l} w_{h k} S_{h}-w_{h l} r_{k} S_{h}+r_{k} S_{l} w_{h h}} \\
\frac{d h}{d \phi}=-\frac{r_{l} w_{h k} S_{\phi}-w_{h l} r_{k} S_{\phi}-w_{h k} S_{l} r_{\phi}+r_{k} S_{l} w_{h \phi}}{-w_{h k} S_{l} r_{h}+r_{l} w_{h k} S_{h}-w_{h l} r_{k} S_{h}+r_{k} S_{l} w_{h h}} \\
\frac{d k}{d \phi}=-\frac{w_{h h} S_{l} r_{\phi}-w_{h \phi} S_{l} r_{h}+S_{h} r_{l} w_{h \phi}-S_{h} w_{h l} r_{\phi}+S_{\phi} w_{h l} r_{h}-S_{\phi} r_{l} w_{h h}}{-w_{h k} S_{l} r_{h}+r_{l} w_{h k} S_{h}-w_{h l} r_{k} S_{h}+r_{k} S_{l} w_{h h}}
\end{gathered}
$$

In order to study the impact of the skill-biased technological change, thus the decrease of $\phi$, we need to determine the sign of equations (A.2)-(A.4). It is easy to check that $S_{l}<0, S_{h}>0, S_{\phi}>0, w_{h k}>0, w_{h l}>0, w_{h h}<0, w_{h \phi}<0, r_{k}<0, r_{l}>0$ and $r_{h}>0$, $r_{\phi}>0$ holds. There are 8 cases for the the sign of equations (A.2) - (A.4). $(+,+,+),(+,+,-)$, $(+,-,-),(-,+,+),(-,+,-),(+,-,+),(-,-,+),(-,-,-)$. From the empirical point of view the case $(+,-,-)$ and $(+,-,+)$ should be studied. Under this setting an increase in $\phi$ leads to a decline in unskilled labor, which is consistent with empirical observations.

The terms in equations (A.2) - (A.4) are quite complicated and make an analytical solution infeasible. The partial derivatives are presented in appendix A.3. Some of the parameters can be fixed: $\alpha=0.35, \psi=0.46, A=1, k=100$ and $u=0.5$. We explain the choice of the parameters in detail. The capital share is assumed to be constant and around 0.35 . The parameter $\psi$ is set to 0.46 in order to match equation (2.24) with empirical data for Poland. The TFP is set arbitrary to 1 , in order to simplify the equation. Also the capital stock $k$ is chosen arbitrarily, because this value does not change the results of the analysis ( $A$ and $k$ disappear after simplification of equations (A.2) and (A.3)). Finally, we chose the definition of skilled/unskilled labor as belonging to categories 1,2,3 and 4,5, thus workers with primary and secondary education are considered as unskilled. Their share in the total population is quite close to 0.5 (see table 2.3). We are left with $h, l$ and $\phi$. Basing on empirical observations, we put the parameters in intervals: $0.2<l<0.5,0.3<h<0.5$ and $0.15<\phi<0.4$. The motivation is provided in section 2.3 and empirical values for $\phi$ can be found in table 2.3. Skilled workers work more than unskilled, thus we assume 
$l<h$. Due to data availability, we pretend that only full-time employed workers are employed and the rest is unemployed. The interesting point is to find the relation between $\phi, h$ and $l$, under which $\frac{d l}{d \phi}>0$ and simultaneously $\frac{d h}{d \phi}<0$. As no analytical closed-form solution exists, we resort to graphical analysis. From empirical data for Poland we obtain an average relationship between $l$ and $h$. Thus, only two variables, namely $h$ and $\phi$ are left. A 3D graph of $\frac{d l}{d \phi}$ and $\frac{d h}{d \phi}$ is presented in figure A.1.

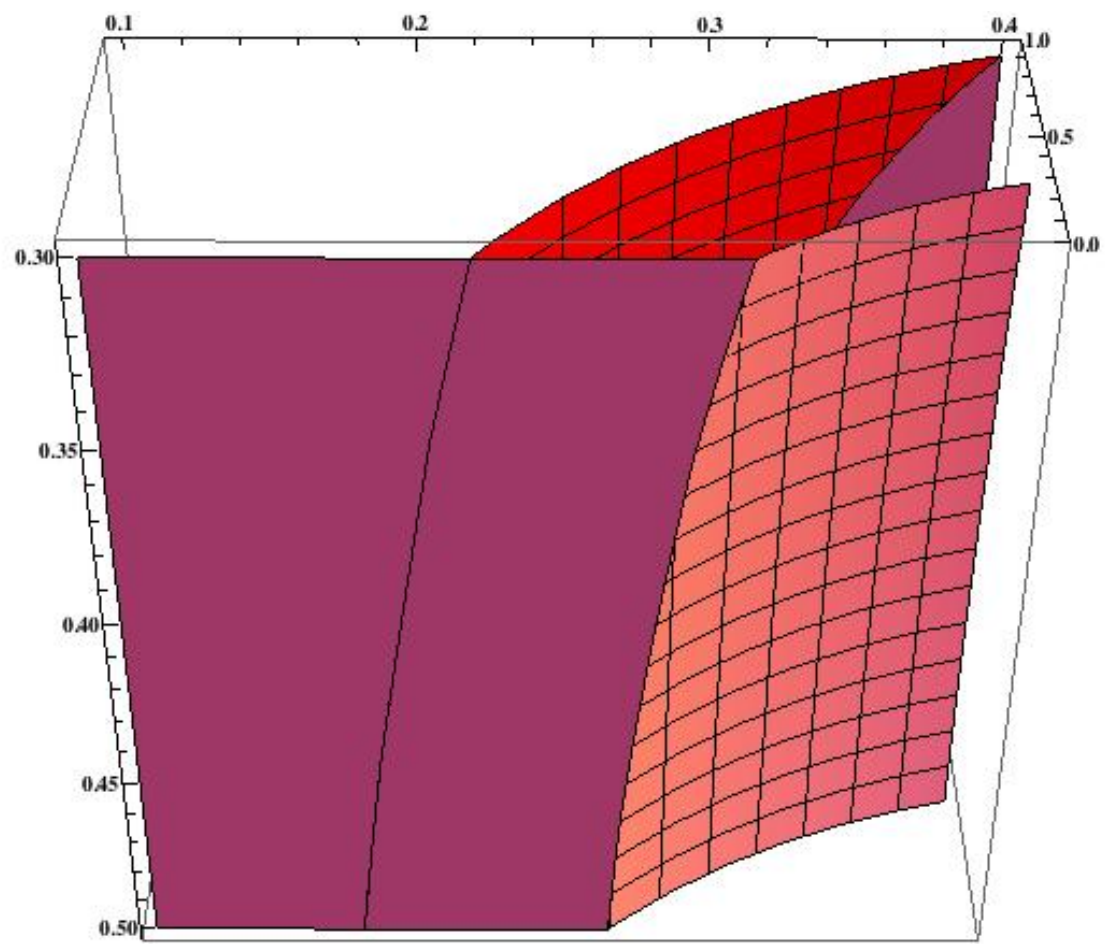

Figure A.1: Graphical representation of $d l / d \phi$ (front) and $d h / d \phi$ (back) (equations (A.2) and (A.3)) under $u=0.51$, and $l=0.61 * h$, for the year 2001. $\phi$ on horizontal axis, $h$ on vertical axis. Values below zero are clipped.

Repeating the procedure with slightly different parameter values results in qualitatively the same picture. For any value of $h$ there exists a range of $\phi$, such that $\frac{d l}{d \phi}>0$ and simultaneously $\frac{d h}{d \phi}<0$ holds. When $u$ decreases, the region moves to the left. When the ration $l / h$ decreases, the intersection of $\frac{d h}{d \phi}$ moves to the right. Skill-biased technological change increases skilled labor supply and decreases unskilled labor supply. The function $d k / d \phi$ is not plotted. It is positive for any observable $\phi$ value. This means that SBTC decreases the physical capital stock when TFP is kept constant.

\section{A.2 Extension - capturing the effect of the multinational company}

In the model studied in this paper, SBTC and neutral technological change are considered as an exogenous process. However, an interesting extension is to endogenize this 
processes. We give a flavor of such an approach in the following section. Multinational companies enter the market and adopt a technology which requires skills and uses them efficiently. This technology spills over to the whole economy. Firms and households consider the skill-biased and neutral technological change as exogenous.

\section{A.2.1 Opening the model to borrowing abroad}

Following Birchenall (2008), the budget constraint is modified in order to capture foreign capital. Households have access to the world capital market and borrow capital at the world interest rate $r$. Let $k$ denote domestic owned capital and $x$ foreign borrowed capital. Households supply the total capital stock $k+x$ to the firms, charging the world interest rate $r$. Due to borrowing constraints, the amount of borrowed capital is bounded, therefore the marginal product of total capital $k+x$ is higher than $r$. This is because $f_{k}(k+x)>f_{k}\left(k^{*}\right)$, where $k^{*}$ is the capital stock such that $f_{k}\left(k^{*}\right)=r$. The household owns the firm and gets the profit. The budget constraint can be written as $\dot{k}=w_{l} u l+w_{h}(1-u) h+r(k+x)-(\delta+n) k-c-r x+\pi$. Borrowing abroad has the same meaning as foreign direct investment, under which foreigners are the owners of the capital (Barro, Mankiw and Sala-i-Martin 1995). The foreigners supply their knowledge as a by-product of borrowing capital. The capital mobility is imperfect, because this rules out the counterfactual instantaneous convergence to the steady state (Barro, Mankiw and Sala-i-Martin 1995) and is consistent with empirics. Similar to Barro, Mankiw and Salai-Martin (1995) domestic physical capital serves as a collateral and moreover, we assume that only a fraction $0<\beta<1$ serves as collateral. We can assume that the world interest rate is lower than the domestic one. Moreover, the countries need to acquire a lot of physical capital, thus the amount borrowed abroad is $x=\beta k$.

\section{A.2.2 Skill-biased technological change}

During the socialistic era in Poland everybody was employed and therefore also all unskilled workers were employed. Consequently, a suboptimal technology was adopted which matched the quite high unskilled labor supply. There were no incentives for the government to upgrade the technology, even though the labor force become more skilled. After the Transition Economies became open economies, MNCs entered the market. The MNC choses a technology which exploits the abilities of both skilled and unskilled workers. Thus, the parameter $\phi$ is much lower in the foreign owned firm than in the domestic firm.

Let $A$ be constant for the moment, thus we look at a single period. We assume that skilled workers are more productive than unskilled workers $(0<\phi<0.5)$. Due to backward linkages technological change spills over to the domestic firms. This results in 
a decreasing $\phi$, which is modeled as a linear combination of the initial productivity $\phi_{0}$ in the host country and the productivity $\phi_{D}$ of the advanced countries. The weight of each component depends on the share of foreign owned physical capital stock $K_{F D I}$ in the total capital stock $K$.

$$
\phi=\phi_{D} \frac{K_{F D I}}{K}+\phi_{0}\left(1-\frac{K_{F D I}}{K}\right)
$$

We observe a significant inflow of FDI in the Transition Economies, thus the ratio $K_{F D I} / K$ increases and technological spillovers take place. This formula can be motivated by a study by Lorentowicz, Marin and Raubold (2005) on the Polish economy. They find a significant positive effect of the log of the ratio of foreign capital to domestic capital on wage inequality and the share of skilled workers. A more general formulation for the relation between SBTC and foreign capital stock is $\phi=g\left(K_{F D I} / K\right)$ with $g^{\prime}\left(K_{F D I} / K\right)<0$. Due to the decrease of $\phi$ it becomes more valuable to be skilled. For example, in Poland the share of workers with primary education in total labor force was 0.21 in 1994 and 0.12 in 2004 (Polish Central Statistical Office 2007). Over time the unemployment rate of workers with primary education increased from 0.12 to 0.25 . This can be considered as a result of the higher demand for skilled labor and increased wage inequality. It became profitable to invest in education. However, we do not study this choice and move to neutral technological change.

\section{A.2.3 Neutral technological change}

The other important effect of MNCs is their impact on TFP growth. To motivate this assumption, we relate to $\mathrm{Xu}$ (2000) who studied the positive effect of affiliates of US firms on TFP in developed countries. His empirical study shows that trade accounts for $60 \%$ and US affiliates account for $40 \%$ of the technology transmission. Over the period 1966-1994 those effects increased TFP in the host countries by 1.34 percentage points annually, on average. The study confirms the presence of the positive effect of the MNCs on the productivity parameter $A$.

We model the neutral technological change as a function of domestic human capital and technological spillovers from the MNCs. The idea of diffusion of knowledge was introduced by Nelson and Phelps (1966). Basing on the formulation of Duczynski (2003) and Benhabib and Spiegel (2005) we formalize the diffusion of technology from the more advanced countries to the host country as:

$$
\frac{\dot{A}}{A}=g+\gamma \frac{\left(\tau A_{D}-A\right)}{A}
$$

where $\dot{A} / A$ denotes the growth of TFP over time. The technology growth is an external- 
ity, coming from the skilled labor force and also from the share of foreign capital. Here $g$ is the constant, exogenous growth rate of TFP in developed countries. The parameter $\gamma$ weights the diffusion of knowledge. It depends on the ratio of foreign owned capital to total capital in the economy, $\gamma=K_{F D I} / K$. This captures the fact that FDI is an important source for international knowledge transfer. $A_{D}$ denotes the TFP of the developed countries and $\tau$ tells which fraction of the developed countries' TFP level can be reached by the transition country. The parameter $\tau$ depends on the human capital level in the host economy. For simplicity we set $\tau=h(1-u)$, thus it depends directly on the share of skilled workers.

Lack of data makes it impossible to calibrate the above equations and this is left for future research. In the present paper both SBTC and TFP growth are purely exogenous and we focus on its effect on the labor market. 


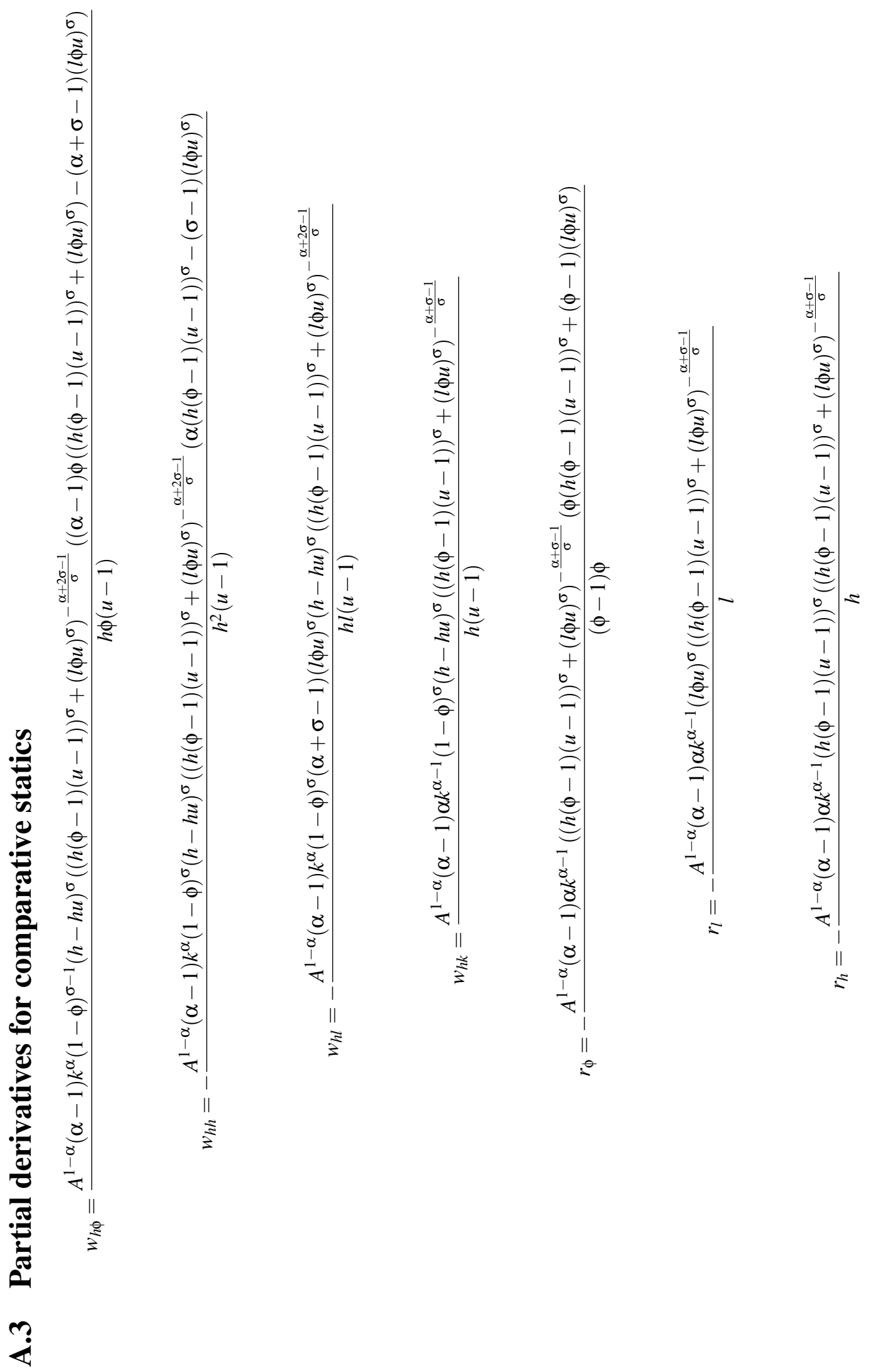




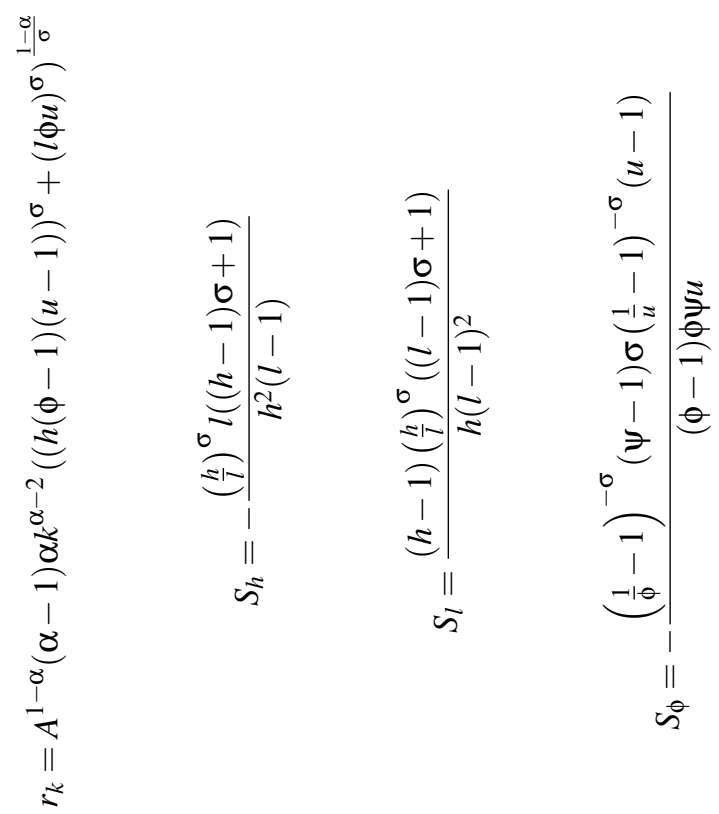




\section{References}

Acemoglu, D. (2002). Technical Change, Inequality, and the Labor Market. Journal of Economic Literature 40(1), 7-72.

Acemoglu, D. and F. Zilibotti (2001). Productivity Differences. The Quarterly Journal of Economics 116(2), 563-606.

Autor, D. H., L. F. Katz and A. B. Krueger (1998). Computing Inequality: Have Computers Changed the Labor Market? Quarterly Journal of Economics 113(4), 11691213.

Barro, R. J. and J. Lee (2000). International Data on Educational Attainment: Updates and Implications. CID Working Paper No. 42.

Barro, R. J., N. G. Mankiw and X. Sala-i-Martin (1995). Capital Mobility in Neoclassical Models of Growth. American Economic Review 85(1), 103-15.

Benhabib, J. and R. E. A. Farmer (1994). Indeterminacy and Increasing Returns. Journal of Economic Theory 63, 19-41.

Benhabib, J. and R. Perli (1994). Uniqueness and Indeterminacy: On the Dynamics of Endogenous Growth. Journal of Economic Theory 63, 113-142.

Benhabib, J. and M. Spiegel (2005). Human Capital and Technology Diffusion. In: P. Aghion and S. Durlauf (Eds.), Handbook of Economic Growth. Elsevier.

Berman, E. J., J. Bound and S. Machin (1998). Implications of skill-biased technological change: International evidence. Quarterly Journal of Economics 113, 12451280.

Birchenall, J. A. (2008). Equilibrium, convergence, and capital mobility in neoclassical models of growth. Economic Letters 99, 10-13.

Caselli, F. and W. J. Coleman (2006). The World Technology Frontier. The American Economic Revue 96(3), 499-521.

Cieślik, A. (2008). Multinational Firms, International Knowledge Flows, and Dual Labor Markets in Developing Economies. Review of Development Economics 12(1), $160-179$.

Duczynski, P. (2003). Convergence in a model with technological diffusion and capital mobility. Economic Modelling 20, 729-740.

Esposito, P. and R. Steher (2007). The sector bias of skill-biased technical change and the rising skill premium in transition economies. wiiw Working Papers 43. 
Galor, O. and O. Moav (2000). Ability Biased Technological Transition, Wage Inequality and Economic Growth. Quarterly Journal of Economics 115, 469-498.

Hall, R. E. and C. I. Jones (1999). Why Do Some Countries Produce So Much More Output Per Worker Than Others? The Quarterly Journal of Economics 114(1), 83-116.

Hendricks, L. (2002). How Important Is Human Capital for Development? Evidence from Immigrant Earnings. The American Economic Review 92(1), 198-219.

International Labor Organization (2008). Labor Statistics. Geneva.

King, R. G. and S. Rebelo (1999). Resuscitating Real Business Cycles. In: J. B. Taylor and M. Woodford (Eds.), Handbook of Macroeconomics. Elsevier.

Lorentowicz, A., D. Marin and A. Raubold (2005). Is human capital losing from outsourcing? Evidence from Poland and Austria. CESifo Working Paper 1616.

Machin, S. (2008). An Appraisal of Economic Research on Changes in Wage Inequality. LABOUR 22(S1), 7-26.

Machin, S. and J. Van Reenen (1998). Technology and Changes in Skill Structure: Evidence from Seven OECD Countries. Quarterly Journal of Economics 113, 12151244.

Nelson, R. R. and E. S. Phelps (1966). Investment in Humans, Technological Diffusion, and Economic Growth. The American Economic Review 56(1/2), 69-75.

Polish Central Statistical Office (2007). Earnings of the employes in the national economy by occupations as of march 1996; Earnings by occupations in October 1998; Structure of wages and salaries by occupation in October: 1999, 2001, 2002, 2004, 2006; Poland. Polish Central Statistical Office GUS.

Prasad, E. (1996). Skill heterogeneity and the business cycle. Canadian Journal of Economics 29(4), 910-929.

Prescott, E. C. (2004). Why Do Americans Work So Much More Than Europeans. Federal Bank of Minneapolis Quarterly Review 28(1), 2-13.

Smarzynska Javorcik, B. (2004). Does Foreign Direct Investment Increase the Productivity of Domestic Firms? In Search of Spillovers through Backward Linkages. The American Economic Review 94(3), 605-627.

Stokey, N. and S. Rebelo (1995). Growth effects of flat-rate taxes. Journal of Political Economy 103(3), 519-550.

US Bureau of Labour Statistics (2008). US Bureau of Labour Statistics. 
Xu, B. (2000). Multinational enterprises, technology diffusion, and host country productivity growth. Journal of Development Economics 62, 477-493. 